\title{
Investigating adolescent stress and body image
}

\author{
Kristen M. Murray*, Don G. Byrne, Elizabeth Rieger \\ Department of Psychology, Building 39, The Australian National University, Canberra ACT 0200, Australia
}

Keywords:

Body image

Stress

Adolescence

Self-esteem

Depression

\begin{abstract}
A B S T R A C T
Adolescent stress is clearly implicated in the development of mental health problems. However, its role in dysfunctional body image, which rises markedly in adolescence, has not been investigated. The present study examined the link between stress and body image, as well as self-esteem and depressive symptoms, in 533 high school students in grades 7 to 10. Results indicated that stress accounts for a sizeable proportion of variance in body image, and the best exploratory model included stress, self-esteem, and gender. Further, specific domains of stressors related to body image differently: peer pressure and school attendance were significant correlates of body image in both genders, while future uncertainty and romantic relationships were significant for males alone. Grade differences in primary variables were also evident for females. This study helps to elucidate the role of adolescent stress in dysfunctional body image and provides insight for future prevention and intervention programs in schools.
\end{abstract}

(c) 2010 The Association for Professionals in Services for Adolescents. Published by Elsevier Ltd. All rights reserved.

The transition to adolescence is accompanied by rapid, unexpected and novel experiences in social, cognitive, physical, emotional and psychological domains (Heaven, 1996). These developmental challenges present opportunities for growth, but they also act as antecedents to stress (Compas, Hinden, \& Gerhardt, 1995; Simmons, 1987). Adolescent stress has received increasing empirical attention as a risk factor for poor mental health. However, it has not yet been investigated in the development of dysfunctional body image. The present study addresses a neglected domain of psychological research: the relationship between stress and body image during adolescence.

Body image is a multifaceted construct involving subjective evaluations of the body. These comprise affective, cognitive and behavioural assessments of size, aesthetics, sensation, function, fitness and health (Pruzinsky \& Cash, 1990). Such appraisals can lead to a perception of the body quite distinct from its objective size and shape (Presnell, Bearman, \& Stice, 2004; Pruzinsky \& Cash, 1990; Ricciardelli \& McCabe, 2001a). It represents an integral component of self-image (Petersen, Schulenberg, Abramowitz, Offer, \& Jarcho, 1984), rendering body image an important construct to understand.

Research shows that dysfunctional evaluations of the body peak during adolescence (Littleton \& Ollendick, 2003) and are a 'normative discontent' (Dohnt \& Tiggemann, 2006; Levine \& Smolak, 2002). This trend is concerning because body image disturbance can have deep and enduring psychological consequences (Bekker \& Boselie, 2002; Rosen, 1990): it is associated with depression and low self-esteem (Pruzinsky \& Cash, 1990), excessive dieting and steroid use (Nowak, 1998; Smolak, 2004), and is a key predictor of eating disturbance and disorders (Stice, 2002). Prevention of eating disorder pathology is vital because of its impact on psychological and physical health, and is difficult to treat (Kenardy, Brown, \& Vogt, 2001; Nowak, 1998). Therefore, a large body of research is dedicated to elucidating causative factors in the development of dysfunctional body image.

\footnotetext{
* Corresponding author. Tel.: +61 0261252783; fax: +61 0261250499.

E-mail addresses: kristen.murray@anu.edu.au (K.M. Murray), don.byrne@anu.edu.au (D.G. Byrne), elizabeth.rieger@anu.edu.au (E. Rieger).
} 
One possible factor in adolescence is stress, although its association with body image has yet to be investigated. Stress results from an interactive process (Cohen, Janicki-Deverts, \& Miller, 2007), involving events (or stressors) that place demands on coping resources and an appraisal that these pose a threat to well-being (Byrne, Davenport, \& Mazanov, 2007). During adolescence, it is the quantity and intensity of transitions, particularly simultaneous and uncontrollable events, that precipitate stress (Compas, Orosan, \& Grant, 1993; Hampel \& Petermann, 2006). This 'adolescent stress' has been recognised as a risk factor for poor mental health (Compas et al., 1995; Hampel \& Petermann, 2006), for example, in health risk behaviours (Byrne \& Mazanov, 2001; Byrne \& Mazanov, 2003; Youngs, Rathge, Mullis, \& Mullis, 1990), depression and low self-esteem (Grant et al., 2003), eating disturbance (Bennett \& Cooper, 1999; Rosen, Tacy, \& Howell, 1990) and eating disorders (Bekker \& Boselie, 2002; McVey, Pepler, Davis, Flett, \& Abdolell, 2005; Rosen, 1990). However, despite theorised links (Levine \& Smolak, 2002), its role in dysfunctional body image has been omitted from research.

This is surprising given the inclusion of stress management in universal school-based programs to prevent body image concerns and disordered eating (McVey \& Davis, 2002; McVey, Davis, Tweed, \& Shaw, 2004; McVey, Tweed, \& Blackmore, 2007). These programs teach communication and social problem-solving skills to enhance adjustment in adolescence. In early adolescent females, such programs have resulted in improved body image satisfaction and self-esteem, and decreased dieting (McVey et al., 2004). Further, reduced internalisation of media body ideals in males and females, and disordered eating in females, have been reported particularly in high-risk participants (McVey et al., 2007). However, like most prevention programs (Paxton, 2002), these improvements were not maintained long-term (McVey et al., 2004, 2007). Research understanding how and what stressors relate to body image dysfunction during adolescence can provide insight to enhance the long-term efficacy of these prevention programs. Such an investigation should take into account two variables: gender and sociocultural influences.

\section{Gender differences in body image and stress}

Gender is a key moderator in body image and adolescent stress research. Females have been shown to report twice the level of body dissatisfaction as their male peers (Kostanski \& Gullone, 1998) and more stress (Grant et al., 2006; Hampel \& Petermann, 2006). However, the gender-dependent nature and outcomes of both body image and stress are being increasingly recognised. Driven by Western cultural ideals, females tend to seek a 'feminine' bodily ideal which is thin and graceful, and report stressors related to the family, friends and romantic partners. In contrast, males may strive for a 'masculine' ideal which is muscular and instrumental, and report stressors in non-interpersonal or self-relevant contexts (Ricciardelli \& McCabe, 2001a; Rudolph, 2002).

Stress highlights the unique socialisation and experiences of females and males in adolescence. As a result, it can provide insight into the development of dysfunctional body image. In fact, research in adolescent females has shown an association between body image satisfaction and fewer stressors (Marcotte, Fortin, Potvin, \& Papillon, 2002), and eating disorder pathology and body dissatisfaction with the cumulative stress of early onset puberty and the commencement of dating in the same year (Smolak, Levine, \& Gralen, 1993). Dietary restraint has also been shown to increase under interpersonal stress in young adult females when they feel they can control their weight but not their same sex friendships (Cain, Bardone-Cone, Abramson, Vohs, \& Joiner, 2009). Therefore, stress can help understand body image disturbance and the role of gender in adolescence.

\section{Sociocultural influences in body image and stress}

Sociocultural research provides insight into the domains of adolescent stress associated with body image dysfunction. Social processes manifest in both the family and peers are important in transmitting and reinforcing cultural ideals of the body (Ata, Ludden, \& Lally, 2007; Dohnt \& Tiggemann, 2006; Jones, 2004; Paxton, Eisenberg, \& Neumark-Sztainer, 2006; Presnell et al., 2004; Ricciardelli \& McCabe, 2001b; Stice \& Shaw, 2002). In the family, comments about the body, encouragement to lose weight (Ricciardelli \& McCabe, 2001a) and modelling of negative eating attitudes and behaviours (by a same sex parent) relate to body image concerns (Levine \& Smolak, 2002). Peer influences differ by gender, with teasing and perceived pressure from same sex peers important for males (Ricciardelli \& McCabe, 2001b), while a subculture equating appearance with acceptance and promoting social comparison predicts body image concerns in females (Ata et al., 2007; Gerner \& Wilson, 2005; Jones, 2004; Ricciardelli \& McCabe, 2001a).

Family and peer relationships also experience marked change during adolescence and are associated with heightened stress (Heaven, 1996). It is possible that stressors in these domains coincide with, initiate or are compounded by negative sociocultural influences on body image.

\section{The nature and direction of the relationship between stress and body image disturbance}

Stress is implicated in the onset of eating disorders (Bekker \& Boselie, 2002; McVey et al., 2005; Rosen, 1990), in which body image disturbance is key (Stice, 2002). An interaction between stress and body image during adolescence could represent an early vulnerability in eating disorder pathology. However, the relationship between stress and mental health is dynamic and complex (Grant et al., 2006), so to understand the stress-body image link, the role of additional psychological variables should be considered. Two constructs displaying consistent bi-directional associations with adolescent stress and 
body image are self-esteem and depression (Allgood-Merten, Lewinsohn, \& Hops, 1990; Byrne \& Mazanov, 2001; Paxton et al., 2006; Ricciardelli \& McCabe, 2001b; Smolak \& Stein, 2006). As such, these are prime candidates for an exploration into the nature of the stress-body image link, and all four constructs have been shown to correlate in females (Marcotte et al., 2002).

\section{The present study}

The aim of the present study is to investigate the relationship between stress and body image in early to mid-adolescent males and females. Adolescent stress is conceptualised as a predictor variable as it has been shown to initiate eating disorder pathology and body dissatisfaction (Smolak et al., 1993). Self-esteem and depressive symptoms will be examined as additional measures of distress to understand the stress-body image link. Gender and grade level differences will be explored, as well as the differential association between domains of adolescent stressors and body image.

\section{Method}

\section{Participants}

The present cross-sectional study surveyed 533 adolescents in grades seven to 10 . The grade and gender breakdown of the surveyed and analysed samples are presented in Tables 1 and 2.

Four non-government schools in Canberra, Australia participated in the study including one co-educational Independent College, and two co-educational and one all girls' Catholic College. Participants were recruited according to class availability in each school so the representation of the larger school ecology is unclear. The Canberra population is demographically homogeneous, thus the generalisability of the sample is high. Information about cultural background was not collected but it is expected the majority of students would be Caucasian.

\section{Measures}

All participants completed the following self-report questionnaires.

Depressive symptoms were measured by the Feelings Scale II, a 15-item scale assessing depressive symptomatology (Byrne et al., 2007). It was developed as part of the validation of the Adolescent Stress Questionnaire as a non-clinical assessment of depressive mood (Byrne et al., 2007). The instrument was constructed with reference to the DSM-IV-TR, the Zung Self-Rating Depression Scale and the NYU School of Medicine website self-assessment scale for depression (http://psych.med.nyu.edu/ patient-care/depression-screening-test). Respondents indicate the extent they have experienced depressive attributes, such as 'I have felt sad or unhappy' or 'I feel guilty without knowing why', in the past week using a 5-point Likert scale ranging from never (0) to always (4). The final score is the sum of all responses within the range of 0-60, higher scores indicating greater depressive symptoms. The scale has a high internal reliability in Canberra adolescents (Cronbach's $\alpha=.91$ ). Convergent and discriminant validity was demonstrated by expected correlations with an anxiety measure $(r=0.67)$ and the Rosenberg Self-Esteem Scale (RSE) $(r=-0.63)$ respectively (Byrne et al., 2007). In the present study, Cronbach's $\alpha$ was 0.88 for the total sample ( 0.88 for females, 0.86 for males).

Self-esteem was measured using the RSE, an established 10-item assessment of global self-esteem (Rosenberg, 1965). Individuals respond to items such as 'On the whole I am satisfied with myself' and 'All in all, I am inclined to feel that I am a failure', using a 4-point Likert scale ranging from strongly disagree (0) to strongly agree (3). Scores range from 0 to 30 with higher scores denoting higher self-esteem. The measure displays strong internal reliability $(\alpha=.88)$ in adolescents (GrayLittle, Williams, \& Hancock, 1997; Polce-Lynch, Myers, Kliewer, \& Kilmartin, 2001), has ranged between $\alpha=.88$ and 0.90 over four years (Robins, Hendin, \& Trzesnieski, 2001), and has a one-week test-retest reliability of $\alpha=.82$ (Fleming \& Courtney, 1984). The RSE demonstrates construct validity with the Single-Item Self-Esteem Scale (Robins et al., 2001) and the Self-Rating Scale (Fleming \& Courtney, 1984). In the present study, Cronbach's $\alpha$ was 0.88 for the total sample (0.89 for females, 0.85 for males).

Adolescent stress was measured by the Adolescent Stress Questionnaire (ASQ) (Byrne et al., 2007), a 58-item measure assessing stressors in all aspects of adolescence. Its items correspond to ten subscales related to home life, school performance, school attendance, romantic relationships, peer pressure, teacher interaction, future uncertainty, school/leisure

Table 1

Grade breakdown for sample.

\begin{tabular}{llccc}
\hline Grade & Total Surveyed & Percentage of Surveyed $(\%)$ & Final Sample $(N)$ & Percentage of $N(\%)$ \\
\hline 7 & 173 & 32.5 & 150 & 36 \\
8 & 104 & 19.5 & 68 & 16.3 \\
9 & 113 & 21.2 & 94 & 22.5 \\
10 & 143 & 26.8 & 105 & 25.5 \\
Total $(N)$ & 533 & 100 & 417 & 100 \\
\hline
\end{tabular}


Table 2

Gender breakdown for sample.

\begin{tabular}{|c|c|c|c|c|}
\hline Gender & Total Surveyed & Percentage of Surveyed (\%) & Final Sample $(N)$ & Percentage of $N(\%)$ \\
\hline Female & 350 & 65.7 & 282 & 67.6 \\
\hline Male & 164 & 30.8 & 130 & 31.2 \\
\hline Not Indicated & 19 & 3.6 & 5 & 1.2 \\
\hline Sample $(N)$ & 533 & 100 & 417 & 100 \\
\hline
\end{tabular}

conflict, financial pressure and emerging adult responsibility. Adolescents respond to each item, for example 'Little or no control over your life' or 'Pressure to fit in with peers', in reference to the preceding year on a 5-point Likert scale ranging from not at all stressful or irrelevant to me (1) to very stressful (5). Total stress scores range between 58 and 290 with higher scores indicating greater stress. The ASQ displays concurrent criterion validity, demonstrated by correlations with anxiety, depression and self-esteem measures (Byrne et al., 2007). One-week test-retest correlation coefficients for each subscale has been shown to range between $r=0.68$ and 0.88 , with seven exceeding $r=0.80$ (Byrne et al., 2007). In the present study, Cronbach's $\alpha$ was 0.96 for the total sample ( 0.95 for females, 0.96 for males). All subscales exceeded $\alpha=.7$ except school attendance for males and the total sample, and all samples on adult responsibility. However, as suggested by Gregory (1992) and Nunnally (1978), these subscales were considered acceptable for the purpose of research.

Body image was measured using the Body Image subscale from the Self-Image Questionnaire for Young Adolescents (SIQYA) (Petersen et al., 1984). This scale measures affective and social comparative aspects of body image. It consists of 11 items, including 'I feel proud of my body' and 'Most of the time I am happy with the way I look'. Respondents indicate how much the items describe them using a 6-point Likert scale ranging from describes me very well (1) to does not describe me at all (6). Scores fall between 11 and 66, lower scores indicating more dysfunctional body image. The scale has displayed an internal reliability of $\alpha=.85$ overall (Polce-Lynch et al., 2001), and for females and males respectively $\alpha=.81$ and $\alpha=.77$ (Petersen et al., 1984), and $\alpha=.82$ and $\alpha=.79$ (Barker $\&$ Galambos, 2003). In the present study, Cronbach's $\alpha$ was 0.84 for the total sample, 0.83 for females and 0.82 for males.

\section{Procedure}

The questionnaires were piloted in 15 adolescents in grades 7 to ten who identified no language or comprehension problems. Power analyses revealed a minimum sample size of $N=300$ was necessary for detecting a medium effect size.

The present research received approval from the ANU Human Research Ethics Committee (HREC) and from the Catholic Education Office (CEO) for relevant schools. The HREC approved passive consent which was used for the Independent school, while the CEO required active parental consent which proceeded in the Catholic schools. Participants were recruited according to class availability in each school and parental information and consent forms were distributed to these students two days prior to data collection. Data was collected in whole class groups with teacher supervision. Letters specifying withdrawal or active consent were collected by researchers before the survey was administered. Students allowed to participate were given a brief verbal introduction describing the areas of enquiry and the voluntary and anonymous nature of the study. Students provided written consent before they could take part. Survey administration utilised 'Turning Point', a technology which projects each question using powerpoint to which students respond using electronic keypads. Responses are automatically saved electronically. During administration, question presentation was controlled manually, resulting in a loss of complete responses to individual questions on occasion due to time restrictions. The survey took 50 min to complete with a maximum of 25 students per class. At the conclusion of data collection, students were verbally debriefed, and information describing the aims of the study and contacts for students encountering difficulties were distributed. Students were given the opportunity to ask questions about the study but rarely did. All statistical analyses were conducted using SPSS.

\section{Results}

Data were examined in accordance with Tabachnick and Fidell (2007) to ensure their suitability for statistical analysis. 112 cases possessed more than $5 \%$ missing data, or displayed inconsistent responses, and were deleted. The remaining missing values were randomly distributed and no variable possessed more than $5 \%$ missing responses. Mean substitution for missing data was used for each variable according to year group. Four male cases with multivariate outliers were deleted. All other statistical assumptions were fulfilled. The final dataset comprised $N=417$ (see Tables 1 and 2 for grade and gender breakdown).

Analyses for the total sample

The relationship between adolescent stress, body image, self-esteem and depressive symptoms was initially investigated using bivariate correlations. Table 3 displays the correlation matrix for the total sample, females and males on the four measures. 
Table 3

Correlation matrix for primary measures.

\begin{tabular}{|c|c|c|c|c|c|}
\hline & Sample & Feelings II & RSE & ASQ & SIQYA-BI \\
\hline \multirow[t]{3}{*}{ Feelings II } & Total & - & & & \\
\hline & Females & - & & & \\
\hline & Males & - & & & \\
\hline \multirow[t]{3}{*}{ RSE } & Total & $-0.716^{* *}$ & & & \\
\hline & Females & $-0.693^{* *}$ & - & & \\
\hline & Males & $-0.706^{* *}$ & - & & \\
\hline \multirow[t]{3}{*}{ ASQ } & Total & $0.611^{* *}$ & $-0.483^{* *}$ & & \\
\hline & Females & $0.582^{* *}$ & $-0.422^{* *}$ & & \\
\hline & Males & $0.616^{* *}$ & $-0.531^{* *}$ & & \\
\hline \multirow[t]{3}{*}{ SIQYA-BI } & Total & $-0.606^{* *}$ & $0.691^{* *}$ & $-0.536^{* *}$ & - \\
\hline & Females & $-0.589^{* *}$ & $0.691^{* *}$ & $-0.520^{* *}$ & - \\
\hline & Males & $-0.542^{* *}$ & $0.602^{* *}$ & $-0.504^{* *}$ & - \\
\hline
\end{tabular}

Note. ${ }^{* *}$ Correlation is significant at $p<.01$.

Since all correlations were significant the relationship between stress, self-esteem and depressive symptoms as independent variables (IV) and body image as the dependent variable (DV), was investigated using linear regression. The $\beta$ coefficients, t-values, $R^{2}$, F values and significance for each combination of IVs on the DV are presented in Table 4.

Table 4 shows that each single IV model was significant at $p<.001$. Stress explained $28.8 \%$ of the variance in body image, $95 \%$ CI $[0.218,0.353]$; self-esteem 47.7\%, 95\%CI [0.411, 0.533]; and depressive symptoms 36.8\%, 95\%CI [0.298, 0.43]. Since all three IVs explained significant variance in body image, a more complex model testing their combined effect was performed using standard multiple regression. As shown in Table 4 (Model 4), this combined model was significant at $p<.001$ and explained $53.5 \%$ of the variance in body image, $95 \% \mathrm{CI}[0.471,0.584]$. In addition, $\beta$ coefficients revealed a significant contribution to the model from stress and self-esteem at $p<.001$, and depressive symptoms at $p<.05$.

\section{Analysis of gender differences}

Gender differences have been consistently identified for adolescent stress, depressive symptoms, body image and selfesteem (Grant et al., 2006; Marcotte et al., 2002; Petersen et al., 1984). To investigate gender differences in the present sample, a one-way between-subjects ANOVA was performed in which gender was entered as a fixed factor, and stress, body image, self-esteem and depressive symptoms as DVs. Cases that did not indicate gender were excluded. The F values, effect sizes ( $\eta$ ), estimated marginal means, power and levels of significance are displayed in Table 5.

Table 5 displays significant gender differences for all primary measures. Females displayed greater stress and depression, and poorer body image and self-esteem, compared to males.

\section{Regression analyses}

The impact of gender on the final model was investigated using multiple regression. This model was performed with four main effects (self-esteem, stress, depression and gender) and all six two-way interactions as IVs. Variables were centered when constructing interaction terms. The $\beta$ coefficients, t-values, model $R^{2}$ and $\mathrm{F}$ values are presented in Table 6.

The model was significant, explaining $54.2 \%$ of the variance in body image, $95 \% \mathrm{CI}[0.469,0.584]$. However, $\beta$ coefficients revealed that only the stress, self-esteem and gender main effects contributed significant variance to the model, so it was run again with only these variables. Table 6 reveals that this model explained $53.3 \%$ of the variance in body image, $95 \% \mathrm{CI}[0.469$, 0.583 ], with self-esteem and stress contributing significantly at $p<.001$, and gender at $p=.01$. Therefore, in the present study, the best exploratory model of body image included stress, self-esteem and gender. The gender main effect was investigated further by running this final model separately for females and males. The $\beta$ coefficients, t-values, model $R^{2}$ and $\mathrm{F}$ values are presented in Table 7.

Table 4

Output for total sample regression analyses.

\begin{tabular}{|c|c|c|c|c|c|}
\hline Model & $R^{2}$ & $F(d f 1, d f 2)$ & IVs & $\beta$ & t-value \\
\hline 1 & 0.288 & $167.650(1415)^{* * *}$ & Stress & -0.536 & $-12.948^{* * *}$ \\
\hline 2 & 0.477 & $378.234(1415)^{* * *}$ & SE & 0.691 & $19.448^{* * *}$ \\
\hline 3 & 0.368 & $241.182(1415)^{* * *}$ & DS & -0.606 & $-15.530^{* * *}$ \\
\hline \multirow[t]{3}{*}{4} & 0.535 & $158.238(3413)^{* * *}$ & Stress & -0.228 & $-5.361^{* * *}$ \\
\hline & & & SE & 0.505 & $10.459^{* * *}$ \\
\hline & & & DS & -0.105 & $-1.970^{*}$ \\
\hline
\end{tabular}

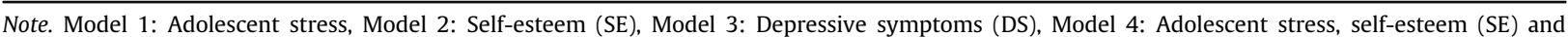
depressive symptoms (DS).

${ }^{*}$ Denotes significant at $p<.05,{ }^{* * *}$ Denotes significant at $p<.001$. 
Table 5

Gender differences on primary measures.

\begin{tabular}{|c|c|c|c|c|c|}
\hline Measure & $\eta^{2}$ & $F(1,411)$ & Power & Gender & EMM \\
\hline \multirow[t]{2}{*}{ Stress } & 0.028 & $11.931^{* * *}$ & 0.931 & Females & 159.065 \\
\hline & & & & Males & 144.699 \\
\hline \multirow[t]{2}{*}{ Body Image } & 0.073 & $32.065^{* * *}$ & 1.000 & Females & 42.814 \\
\hline & & & & Males & 48.779 \\
\hline \multirow[t]{2}{*}{ Self-Esteem } & 0.062 & $27.324^{* * *}$ & 0.999 & Females & 18.292 \\
\hline & & & & Males & 21.288 \\
\hline \multirow[t]{2}{*}{ Depression } & 0.064 & $27.891^{* * *}$ & 1.000 & Females & 24.447 \\
\hline & & & & Males & 19.404 \\
\hline
\end{tabular}

$\mathrm{EMM}=$ Estimated Marginal Means.

Note. ${ }^{* * *}$ Denotes significant at $p<.001$.

Table 7 reveals that the final model is significant for females and males at $p<.001$, explaining $54.1 \%$ of variance in body image for females, $95 \% \mathrm{CI}[0.464,0.60]$, and $41 \%$ for males, $95 \% \mathrm{CI}[0.276,0.509]$. $\beta$ coefficients revealed significant contributions from stress and self-esteem at $p<.001$ in females and males, but stress was significant at $p<.01$ for males.

\section{Analysis of stressor domains}

\section{Regression analyses}

Sociocultural research highlights the influence of family and peers on body image (Ricciardelli \& McCabe, 2001b). These domains also incur substantial stress during adolescence (Heaven, 1996). Therefore, the differential impact of dimensions of stressors on body image was explored using ASQ subscales. Home life and peer pressure were expected to be significant. A standard multiple regression with all ASQ subscales as IVs, and body image as the DV, was performed separately for females and males due to the significance of gender. The $\beta$ coefficients, t-values, model $R^{2}$ and $\mathrm{F}$ values are reported in Table 8 .

The model was significant in females and males at $p<.001$, explaining $30.4 \%$ of the variance in body image for females, $95 \%$ CI $[0.193,0.362]$. However, $\beta$ coefficients indicated that only peer pressure $(p<.001)$ and school attendance $(p<.05)$ contributed significant unique variance to the model. The model explained $46.4 \%$ of the variance for males, $95 \% \mathrm{CI}$ [0.288, 0.529]. Here, $\beta$ coefficients revealed significant contributions from four ASQ subscales: peer pressure $(p<.001)$, school attendance $(p=.001)$, future uncertainty $(p<.01)$ and romantic relationships $(p<.05)$. Home life did not reach significance for females or males.

\section{Analysis of grade level differences}

Grade level differences were investigated to see whether age influences how stressor domains relate to body image. This was initially conducted using a one-way between-subjects ANOVA in the female and male samples separately. Grade was entered as a fixed factor, and stress, body image, self-esteem and depression entered as DVs. Significant grade level differences were apparent only for females. F values, effect sizes, power, marginal means and $95 \%$ confidence intervals are presented for females in Table 9 .

Table 9 reveals significant grade level differences for females on all primary measures. Trends indicate that stress was greatest for females in Grade 10, body image was worst in Grade 7, and self-esteem and depressive symptoms were of greatest

Table 6

Full model multiple regression.

\begin{tabular}{|c|c|c|c|c|c|}
\hline Model & $R^{2}$ & $F(d f 1, d f 2)$ & IVs & $\beta$ & t-value \\
\hline 1 & 0.542 & $47.527(10,401)^{* * *}$ & $\begin{array}{l}\text { Stress } \\
\text { SE } \\
\text { DS } \\
\text { Gender } \\
\text { SE } \times \text { Stress } \\
\text { SE } \times \text { DS } \\
\text { Stress } \times \text { DS } \\
\text { SE } \times \text { Gender } \\
\text { Stress } \times \text { Gender } \\
\text { DS } \times \text { Gender }\end{array}$ & $\begin{array}{r}-0.230 \\
0.464 \\
-0.096 \\
-0.92 \\
-0.064 \\
0.028 \\
-0.053 \\
0.072 \\
-0.030 \\
0.047\end{array}$ & $\begin{array}{c}-4.974^{* * *} \\
8.652^{* * *} \\
-1.608 \\
-2.547^{*} \\
-1.185 \\
0.562 \\
-1.043 \\
1.380 \\
-0.654 \\
0.781\end{array}$ \\
\hline 2 & 0.533 & $155.170(3,408)^{* * *}$ & $\begin{array}{l}\text { Stress } \\
\text { SE } \\
\text { Gender }\end{array}$ & $\begin{array}{r}-0.261 \\
0.538 \\
-0.091\end{array}$ & $\begin{array}{c}-6.759^{* * *} \\
13.696^{* * *} \\
-2.597^{* *}\end{array}$ \\
\hline
\end{tabular}

Note. Model 1: Full Model with four main effects and six two-way interactions as IVs, Model 2: Stress, Self-esteem and gender as IVs, SE = Self-esteem, DS $=$ Depressive symptoms.

${ }^{*}$ Denotes significant at $p<.05,{ }^{* *}$ Denotes significant at $p=.01,{ }^{* * *}$ Denotes significant at $p<.001$. 
Table 7

Standard multiple regression output for females and males.

\begin{tabular}{|c|c|c|c|c|c|}
\hline Gender & $R^{2}$ & $\mathrm{~F}(\mathrm{df} 1, \mathrm{df} 2)$ & IVs & $\beta$ & t-value \\
\hline \multirow[t]{2}{*}{ Females } & 0.541 & $164.559(2,279)^{* * *}$ & Stress & -0.278 & $-6.204^{* * *}$ \\
\hline & & & SE & 0.574 & $12.836^{* * *}$ \\
\hline \multirow[t]{2}{*}{ Males } & 0.410 & $44.138(2,127)^{* * *}$ & Stress & -0.257 & $-3.194^{* * *}$ \\
\hline & & & SE & 0.466 & $5.792^{* *}$ \\
\hline
\end{tabular}

Note. ${ }^{* *}$ Denotes significant at $p<.01,{ }^{* * *}$ Denotes significant at $p<.001$.

concern in Grade 9. Considerable overlap is evident in the 95\% confidence intervals for both the total and female sample. As a result, no further exploration was pursued to avoid overly determined analyses or a loss of power.

\section{Discussion}

The current study provided the first exploration of the relationship between stress and body image during adolescence, and the role of self-esteem, depressive symptoms, gender, and domains of adolescent stress.

Bivariate correlations revealed that higher reported levels of stress were associated with dysfunctional body image, lower self-esteem and greater depressive symptoms, while self-esteem related positively, and depressive symptoms negatively, to body image. These associations are consistent with previous research (Marcotte et al., 2002) but the present study confirms them for females as well as males.

Regression analyses indicated that stress during adolescence accounts for between $21 \%$ and $35 \%$ of the variance in body image. These results suggest that adolescent stress may play an important role in body image. Self-esteem explained the greatest unique variance in body image while depressive symptoms were also significant, both consistent with previous research (Ata et al., 2007; Marcotte et al., 2002; Petersen et al., 1984; Ricciardelli \& McCabe, 2001b).

The combination of stress, self-esteem and depressive symptoms accounted for $47 \%-58 \%$ of the variance in body image scores. This model accounted for more variance than any single IV model, highlighting the complexity of body image. These findings contribute to its theoretical foundation by elucidating the role of stress, self-esteem and depressive symptoms as individual and collective markers of risk.

Exploration of gender differences on primary variables revealed trends consistent with the literature: females reported greater stress (Rudolph \& Hammen, 1999) and depressive symptoms (Hankin, 2006), and more negative self-esteem and body image (Croghan et al., 2006) compared to males. Gender was included in the combined multiple regression model which explained 46.9 to $58.4 \%$ of the variance in body image. However, only the stress, self-esteem and gender main effects made significant contributions. This suggests that while depressive symptoms make an important contribution to body image in adolescence, gender was more salient in this sample. Thus, the final model included stress, self-esteem and gender, explaining 46.9 to $58.3 \%$ of the variance in body image.

The gender main effect was investigated further by examining this model separately for females and males. Both models were significant and while a greater proportion of variance was explained for females, 95\% confidence intervals overlapped. It is not surprising that the model was stronger for females because it assessed internalising symptoms, more commonly associated with psychopathology in females than males (Grant et al., 2006). In addition, it is unlikely that stress and selfesteem would relate to body image in the same way for females and males, underlining the need for more research on body image in males (Cafri et al., 2005; McCabe \& Ricciardelli, 2004). Future research could consider the role of externalising behaviours. These are associated with adolescent stress in males (Grant et al., 2006) and reflect the adoption of body change strategies, such as exercise, to enhance muscularity and improve body image (Cafri et al., 2005). The present study provides insight into the unique development of body image in females and males, but more research is needed to understand these pathways.

Findings related to stressor domains provided insight into the role of stress in dysfunctional body image in females and males. Due to the importance of the family and peers in body image disturbance (Ata et al., 2007; Gerner \& Wilson, 2005;

Table 8

Regression output for ASQ subscales analysis in females and males.

\begin{tabular}{|c|c|c|c|c|c|}
\hline Gender & $R^{2}$ & $\mathrm{~F}(\mathrm{df} 1, \mathrm{df} 2)$ & Significant subscales & $\beta$ & t-value \\
\hline Females & 0.304 & $11.811(10,271)^{* * *}$ & $\begin{array}{l}\text { PP } \\
\text { SA }\end{array}$ & $\begin{array}{l}-0.319 \\
-0.153\end{array}$ & $\begin{array}{l}-4.593^{* * *} \\
-2.274^{*}\end{array}$ \\
\hline Males & 0.464 & $10.309(10,119)^{* * *}$ & $\begin{array}{l}\text { PP } \\
\text { SA } \\
\text { FU } \\
\text { RR }\end{array}$ & $\begin{array}{r}-0.361 \\
-0.295 \\
-0.288 \\
0.174\end{array}$ & $\begin{array}{c}-3.683^{* * *} \\
-3.325+ \\
2.997^{* *} \\
2.120^{*}\end{array}$ \\
\hline
\end{tabular}

$\mathrm{PP}=$ Peer Pressure, $\mathrm{SA}=$ School Attendance, $\mathrm{FU}=$ Future Uncertainty, $\mathrm{RR}=$ Romantic Relationships. Note. ${ }^{*}$ denotes significant at $p<.05$, ${ }^{* *}$ denotes significant at $p<.01{ }^{* * *}$ denotes significant at $p<.001,+$ denotes significant at $p=.001$. 
Table 9

Age differences for females on primary measures.

\begin{tabular}{|c|c|c|c|c|c|c|}
\hline & \multirow[t]{2}{*}{$\mathrm{F}(3,278)$} & \multirow[t]{2}{*}{ Partial Eta Squared } & \multirow[t]{2}{*}{ Observed Power } & \multirow[t]{2}{*}{ Estimated Marginal Means } & \multicolumn{2}{|c|}{ 95\% Confidence Interval } \\
\hline & & & & & $\mathrm{L}$ & $\mathrm{U}$ \\
\hline Stress & $3.089^{*}$ & 0.032 & 0.719 & & & \\
\hline Year 7 & & & & 149.658 & 141.812 & 157.504 \\
\hline Year 8 & & & & 162.651 & 151.900 & 173.402 \\
\hline Year 9 & & & & 160.552 & 151.218 & 169.886 \\
\hline Year 10 & & & & 166.869 & 158.236 & 175.501 \\
\hline Body Image & $4.726^{* *}$ & 0.049 & 0.896 & & & \\
\hline Year 7 & & & & 45.529 & 43.522 & 47.536 \\
\hline Year 8 & & & & 42.532 & 39.782 & 45.281 \\
\hline Year 9 & & & & 39.62 & 37.233 & 42.008 \\
\hline Year 10 & & & & 42.443 & 40.235 & 44.650 \\
\hline Self-esteem & $3.074^{*}$ & 0.032 & 0.716 & & & \\
\hline Year 7 & & & & 18.732 & 17.637 & 19.287 \\
\hline Year 8 & & & & 19.509 & 18.009 & 21.009 \\
\hline Year 9 & & & & 16.667 & 15.365 & 19.969 \\
\hline Year 10 & & & & 18.366 & 17.161 & 19.570 \\
\hline Depression & $3.915^{* *}$ & 0.041 & 0.826 & & & \\
\hline Year 7 & & & & 22.453 & 20.597 & 24.308 \\
\hline Year 8 & & & & 23.144 & 20.601 & 25.686 \\
\hline Year 9 & & & & 27.002 & 24.794 & 29.210 \\
\hline Year 10 & & & & 25.515 & 23.474 & 27.557 \\
\hline
\end{tabular}

Note. ${ }^{*}$ Denotes significant at $p<.05$, ${ }^{* *}$ Denotes significant at $p<.01$.

Jones, 2004) and adolescent stress (Heaven, 1996), it was expected that stressors of an interpersonal nature, specifically the home life and peer pressure ASQ subscales, would be significant.

Results indicated that for females this model explained $19.3 \%-36.2 \%$ of the variance in body image, and for males $28.8 \%-52.9 \%$. However, while peer pressure and school attendance contributed significantly to both, future uncertainty and romantic relationships were significant only for males.

Peer pressure provided the greatest unique contribution to dysfunctional body image in females and males. This scale measures hassles involving peer acceptance and appearance (Byrne et al., 2007). However, it is unlikely that the processes underlying this association would be the same for females and males. Body image in females is influenced by peer group subcultures that equate appearance with acceptance (Gerner \& Wilson, 2005). These influences reflect adolescent stress research which highlights the susceptibility of females to interpersonal stressors (Rudolph, 2002; Rudolph \& Hammen, 1999). Therefore, peer group stress may relate to dysfunctional body image in females because these relationships are valued and attractiveness is believed to ensure their stability.

For males, negative body image and the adoption of body change strategies are influenced by teasing or perceived pressure from male peers (Ricciardelli \& McCabe, 2001b). Peer teasing can be understood as a threat to masculinity and reflects stressors of a non-interpersonal, or self-relevant, nature (Rudolph, 2002). The relationship between peer pressure stressors and body image in the present study could reflect similar processes.

Stress of school attendance also significantly predicted body image problems in both females and males. Adolescence involves numerous changes but the academic and social demands of high school are particularly stressful (Heaven, 1996; Petersen et al., 1984). Further, because school attendance is compulsory, exposure to this stressor is chronic and uncontrollable, characteristics that have been associated with poor self-esteem and psychopathology (Compas et al., 1995; Hampel \& Petermann, 2006). The present findings therefore extend previous research regarding the negative correlates of school stressors to include negative body image.

Future uncertainty and romantic relationships were also significant correlates of body image disturbance in males. The first scale relates to concerns, pressure or decisions about the future (Byrne et al., 2007). These represent ambiguous and uncontrollable stressors that might deflate self-esteem and foster negative perceptions of the body (Compas et al., 1995; Heaven, 1996). The significance of romantic relationship stressors is interesting since females are more sensitive to stressors in interpersonal domains (Rudolph, 2002). The positive $\beta$ coefficient suggests that as stressors in this domain increase, body image becomes more positive. This might indicate that for males, stressors in intimate relationships provide the opportunity for self-enhancement, or that being in a relationship provides a positive influence on body image that compensates for any negative effects of stress. The effects of home life did not reach significance in any model. It is possible that the items on this scale did not correspond to the family pressures associated with dysfunctional body image, such as negative comments from family members regarding the adolescent's body shape and weight.

Analysis of grade differences revealed significant effects for females only. Trends indicated that stress was greatest in Grade 10, body image most negative in Grade 7, and self-esteem and depressive symptoms of most concern in Grade 9. These findings reflect research suggesting late adolescence incurs the most stress (Hampel \& Petermann, 2006), and that body 
image concerns peak in early adolescence around puberty (Littleton \& Ollendick, 2003). Self-esteem (Zimmerman, Copeland, Shope, \& Dielman, 1997) and depressive symptoms (Hankin, 2006) have also been shown to get worse over time in adolescent females. These analyses highlight the impact of developmental demands on perceptions of the self and body in adolescent females. The absence of grade differences for males might reflect stability over time, or a loss of statistical power due to uneven grade composition. Considerable overlap was apparent in the confidence intervals for these analyses, precluding further exploration. Additional research is needed to clarify these findings and understand how stressors relate to body image over time in females and males.

The present study had several limitations. First, its cross-sectional design precludes inferences of causality. Research has shown body dissatisfaction to predict depressive disorder in adolescent females over four years (Stice, Hayward, Cameron, Killen, \& Taylor, 2000), and thus depressive symptoms could be conceptualised as an outcome variable. Further, it is possible that body image problems are a source of stress. Longitudinal research is needed to clarify these questions of directionality. Second, since data collection utilised one all girls' school, the gender composition of the sample was not ideal. Third, as only one measure of body image was used, these findings should be replicated to assess the generality of the stressbody image link across dimensions of body image. The single informant design also raises the possibility of shared method variance.

A considerable strength of the present study is that it is the first to investigate the role of adolescent stress in body image. This study can inform universal school-based programs to improve body image and prevent the onset of eating disorder pathology (McVey \& Davis, 2002; McVey et al., 2004; McVey et al., 2007). The findings of the present study may help to enhance the long-term efficacy of these programs by targeting dimensions of stress relevant for body image problems in males and females.

The present study identified a strong relationship between adolescent stress and body image, and highlighted the importance of self-esteem and gender in this process. By contributing to the theoretical framework of poor body image in females and males, stress may prove to be a missing link in effective early identification, prevention and intervention.

\section{Acknowledgements}

We wish to thank Ms Kate Fenton for her contribution to the development of the current study design and data collection.

\section{References}

Allgood-Merten, B., Lewinsohn, P. M., \& Hops, H. (1990). Sex differences and adolescent depression. Journal of Abnormal Psychology, 99, 55-63.

Ata, R. N., Ludden, A. B., \& Lally, M. M. (2007). The effects of gender and family, friend and media influences on eating behaviours and body image during adolescence. Journal of Youth and Adolescence, 36, 1024-1037.

Barker, E. T., \& Galambos, N. L. (2003). Body dissatisfaction in adolescent girls and boys: risk and resource factors. The Journal of Early Adolescence, 23, $141-165$.

Bekker, M. H. J., \& Boselie, K. A. H. M. (2002). Gender and stress: is gender role stress? A re-examination of the relationship between feminine gender role stress and eating disorders. Stress and Health, 18, 141-149.

Bennett, D. A., \& Cooper, C. L. (1999). Eating disturbance as a manifestation of the stress process: a review of the literature. Stress Medicine, 16, 167-182.

Byrne, D. G., Davenport, S. C., \& Mazanov, J. (2007). Profiles of adolescent stress: the development of the adolescent stress questionnaire (ASQ). Journal of Adolescence, 30, 393-416.

Byrne, D. G., \& Mazanov, J. (2001). Self-esteem, stress and cigarette smoking in adolescents. Stress and Health, 17, 105-110.

Byrne, D. G., \& Mazanov, J. (2003). Adolescent stress and future smoking behaviour: a prospective investigation. Journal of Psychosomatic Research, 54, 313-321.

Cafri, G., Thompson, J. K., Ricciardelli, L., McCabe, M., Smolak, L., \& Yesalis, C. (2005). Pursuit of the muscular ideal: physical and psychological consequences and putative risk factors. Clinical Psychology Review, 25, 215-239.

Cain, A. S., Bardone-Cone, A. M., Abramson, L. Y., Vohs, K. D., \& Joiner, T. E. (2009). Prospectively predicting dietary restraint: the role of interpersonal selfefficacy, weight/shape self-efficacy, and interpersonal stress. International Journal of Eating Disorders.

Cohen, S., Janicki-Deverts, D., \& Miller, G. E. (2007). Psychological stress and disease. Journal of the American Medical Association, 298, $1685-1687$.

Compas, B. E., Hinden, B. R., \& Gerhardt, C. A. (1995). Adolescent development: pathways and processes of risk and resilience. Annual Review of Psychology, $46,265-293$

Compas, B. E., Orosan, P. G., \& Grant, K. E. (1993). Adolescent stress and coping: implications for psychopathology during adolescence. Journal of Adolescence, $16,331-349$.

Croghan, I. T., Bronars, C., Patten, C. A., Schroeder, D. R., Nirelli, L. M., Thomas, J. L., et al. (2006). Is smoking related to body image satisfaction, stress, and selfesteem in young adults? American Journal of Health Behavior, 30, 322-333.

Dohnt, H. K., \& Tiggemann, M. (2006). Body image concerns in young girls: the role of peers and media prior to adolescence. Journal of Youth and Adolescence, 35, 141-151.

Fleming, J. S., \& Courtney, B. E. (1984). The dimensionality of self-esteem II: hierarchical facet model for revised measurement scales. Journal of Personality and Social Psychology, 46, 404-421.

Gerner, B., \& Wilson, P. H. (2005). The relationship between friendship factors and adolescent girls' body image concern, body dissatisfaction, and restrained eating. International Journal of Eating Disorders, 37, 313-320.

Grant, K. E., Compas, B. E., Stuhlmacher, A. F., Thurm, A. E., McMahon, S. D., \& Halpert, J. A. (2003). Stressor and child and adolescent psychopathology: moving from markers to mechanisms of risk. Psychological Bulletin, 129, 442-466.

Grant, K. E., Compas, B. E., Thurm, A. E., McMahon, S. D., Gipson, P. Y., Campbell, A. J., et al. (2006). Stressors and child and adolescent psychopathology: evidence of moderating and mediating effects. Clinical Psychology Review, 26, 257-283.

Gray-Little, B., Williams, V. S. L., \& Hancock, T. D. (1997). An item response theory analysis of the Rosenberg Self-Esteem Scale. Personality and Social Psychology Bulletin, 23, 443-451.

Gregory, R. J. (1992). Psychological testing: History, principles and applications. Needham Heights, MA: Allyn \& Bacon.

Hampel, P., \& Petermann, G. (2006). Perceived stress, coping, and adjustment in adolescents. Journal of Adolescent Health, 38, 409-415.

Hankin, B. L. (2006). Adolescent depression: description, causes and interventions. Epilepsy and Behaviour, 8, 102-114.

Heaven, P. (1996). Adolescent health: The role of individual differences. London: Routledge. 
Jones, D. C. (2004). Body image among adolescent girls and boys: a longitudinal study. Developmental Psychology, 40, 823-835.

Kenardy, J., Brown, W. J., \& Vogt, E. (2001). Dieting and health in young Australian women. European Eating Disorders Review, 9, $242-254$.

Kostanski, M., \& Gullone, E. (1998). Adolescent body image dissatisfaction: relationships with self-esteem, anxiety, and depression controlling for body mass. Journal of Child Psychology and Psychiatry, 39, 255-262.

Levine, M. P., \& Smolak, L. (2002). Body image development in adolescence. In T. F. Cash, \& T. Pruzinsky (Eds.), Body image: A handbook of theory, research \& clinical practice (pp. 74-82). New York: The Guilford Press.

Littleton, H. L., \& Ollendick, T. (2003). Negative body image and disordered eating behaviour in children and adolescents: what places youth at risk and how can these problems be prevented? Clinical Child and Family Psychology Review, 6, 51-66.

Marcotte, D., Fortin, L., Potvin, P., \& Papillon, M. (2002). Gender differences in depressive symptoms during adolescence: role of gender-typed characteristics, self-esteem, body image, stressful life events, and pubertal status. Journal of Emotional and Behavioral Disorders, 10, $29-42$.

McCabe, M. P., \& Ricciardelli, L. A. (2004). Body image dissatisfaction among males across the lifespan: a review of past literature. Journal of Psychosomatic Research, 56, 675-685.

McVey, G. L., \& Davis, R. (2002). A program to promote positive body image: a 1-year follow-up evaluation. The Journal of Early Adolescence, 22, 96-108.

McVey, G. L., Davis, R., Tweed, S., \& Shaw, B. F. (2004). Evaluation of a school-based program designed to improve body image satisfaction, global selfesteem, and eating attitudes and behaviours: a replication study. International Journal of Eating Disorders, 36, 1-11.

McVey, G. L., Pepler, D., Davis, R., Flett, G. L., \& Abdolell, M. (2005). Risk and protective factors associated with disordered eating during early adolescence. Journal of Early Adolescence, 22, 75-95.

McVey, G., Tweed, S., \& Blackmore, E. (2007). Healthy schools-healthy kids: a controlled evaluation of a comprehensive universal eating disorder prevention program. Body Image, 4, 115-136.

Nowak, M. (1998). The weight-conscious adolescent: body image, food intake, and weight-related behavior. Journal of Adolescent Health, 23, 389-398.

Nunnally, J. C. (1978). Psychometric theory (1st ed.). New York: McGraw-Hill.

Paxton, S. J. (2002). Research review of body image programs: an overview of body image dissatisfaction prevention interventions. Retrieved 10.04 .08 . http://www.health.vic.gov.au/healthpromotion/downloads/research_review.pdf.

Paxton, S. J., Eisenberg, M. E., \& Neumark-Sztainer, D. (2006). Prospective predictors of body dissatisfaction in adolescent girls and boys: a five-year longitudinal study. Developmental Psychology, 42, 888-899.

Petersen, A. C., Schulenberg, J. E., Abramowitz, R. H., Offer, D., \& Jarcho, H. D. (1984). A self-image questionnaire for young adolescents (SIQYA): reliability and validity studies. Journal of Youth and Adolescence, 13, 93-111.

Polce-Lynch, M., Myers, B. J., Kliewer, W., \& Kilmartin, C. (2001). Adolescent self-esteem and gender: exploring relations to sexual harassment, body image, media influence, and emotional expression. Journal of Youth and Adolescence, 30, 225-244.

Presnell, K., Bearman, S. K., \& Stice, E. (2004). Risk factors for body dissatisfaction in adolescent boys and girls: a prospective study. The International Journal of Eating Disorders, 36, 389-401.

Pruzinsky, T., \& Cash, T. F. (1990). Integrative themes in body-image development, deviance, and change. In T. G. Cash, \& T. Pruzinsky (Eds.), Body images: Development, deviance and change (pp. 338-349). New York: The Guilford Press.

Ricciardelli, L. A., \& McCabe, M. P. (2001a). Children's body image concerns and eating disturbance: a review of the literature. Clinical Psychology Review, 21, 325-344.

Ricciardelli, L. A., \& McCabe, M. P. (2001b). Self-esteem and negative affect as moderators of sociocultural influences on body dissatisfaction, strategies to decrease weight, and strategies to increase muscles among adolescent boys and girls. Sex Roles, 44, 189-207.

Robins, R. W., Hendin, H. M., \& Trzesnieski, K. H. (2001). Measuring global self-esteem: construct validation of a single-item measure and the Rosenberg Self-Esteem Scale. Personality and Social Psychology Bulletin, 27, 151-161.

Rosen, J. C. (1990). Body-image disturbances in eating disorders. In T. G. Cash, \& T. Pruzinsky (Eds.), Body images: Development, deviance and change (pp. 190214). New York: The Guilford Press.

Rosen, J. C., Tacy, B., \& Howell, D. (1990). Life stress, psychological symptoms and weight reducing behaviour in adolescent girls: a prospective analysis. International Journal of Eating Disorders, 9, 17-26.

Rosenberg, M. (1965). Society and the adolescent self-image. Princeton, NJ: Princeton University Press.

Rudolph, K. (2002). Gender differences in emotional responses to interpersonal stress during adolescence. Journal of Adolescent Health, 30S, 3-13.

Rudolph, K. D., \& Hammen, C. (1999). Age and gender as determinants of stress exposure, generation, and reaction in youngsters: a transactional perspective. Child Development, 70, 660-677.

Simmons, R. G. (1987). Social transition and adolescent development. Adolescent Social Behavior and Health: New Directions for Child Development, 37, 33-61.

Smolak, L. (2004). Body image in children and adolescents: where do we go from here? Body Image, 1, 15-28.

Smolak, L., Levine, M. P., \& Gralen, S. (1993). The impact of puberty and dating on eating problems among middle school girls. Journal of Youth and Adolescence, 22, 355-368.

Smolak, L., \& Stein, J. A. (2006). The relationship of drive for muscularity to sociocultural factors, self-esteem, physical attributes gender role, and social comparison in middle school boys. Body Image, 3, 121-129.

Stice, E. (2002). Risk and maintenance factors for eating pathology: a meta-analytic review. Psychological Bulletin, 128, 825-848.

Stice, E., Hayward, C., Cameron, R. P., Killen, J. D., \& Taylor, C. B. (2000). Body-image and eating disturbances predict onset of depression among female adolescents: a longitudinal study. Journal of Abnormal Psychology, 109, 438-444.

Stice, E., \& Shaw, H. (2002). Role of body dissatisfaction in the onset and maintenance of eating pathology: a synthesis of research findings. Journal of Psychosomatic Research, 53, 985-993.

Tabachnick, B. G., \& Fidell, L. S. (2007). Using multivariate statistics (5th ed.). Boston: Pearson International.

Youngs, G. A., Jr., Rathge, R., Mullis, R., \& Mullis, A. (1990). Adolescent stress and self-esteem. Adolescence, 25, 333-341.

Zimmerman, M. A., Copeland, L.a., Shope, J. T., \& Dielman, T. E. (1997). A longitudinal study of self-esteem: implications for adolescent development. Journal of Youth and Adolescence, 26, 117-141. 